\title{
The prognostic role of pathologic invasive component size, excluding lepidic growth, in stage I lung adenocarcinoma
}

\author{
Yasuhiro Tsutani, MD, PhD, ${ }^{\mathrm{a}}$ Yoshihiro Miyata, $\mathrm{MD}, \mathrm{PhD},{ }^{\mathrm{a}}$ Takahiro Mimae, $\mathrm{MD}, \mathrm{PhD},{ }^{\mathrm{a}}$ \\ Kei Kushitani, MD, $\mathrm{PhD},{ }^{\mathrm{b}}$ Yukio Takeshima, $\mathrm{MD}, \mathrm{PhD},{ }^{\mathrm{b}}$ Masahiro Yoshimura, $\mathrm{MD}, \mathrm{PhD},{ }^{\mathrm{c}}$ and \\ Morihito Okada, $\mathrm{MD}, \mathrm{PhD}^{\mathrm{a}}$
}

Objectives: We performed an investigation of the prognostic significance of the invasive component size,
excluding lepidic growth, in lung adenocarcinoma patients. Methods: The data from 603 patients with completely resected pathologic stage I lung adenocarcinomas were
analyzed retrospectively to determine the relationship between pathologic tumor size and surgical results.

\begin{abstract}
Results: The median tumor size of the total growth and the invasive component were $2.2 \mathrm{~cm}$ and $1.3 \mathrm{~cm}$, respectively. There were significant differences in recurrence-free survival between patients classified on the basis of invasive component sizes $(\leq 0.5 \mathrm{~cm}$ vs $0.5-2.0 \mathrm{~cm}, P<.001$; and $0.5-2.0 \mathrm{~cm}$ vs $>2.0 \mathrm{~cm} ; P=.026)$. A multivariate Cox regression analysis showed that invasive component size $(P=.002)$, age, sex, and lymphatic invasion were independent prognostic factors for recurrence-free survival, whereas total tumor size was not $(P=.068)$. There were no significant differences in recurrence-free survival between patients who received adjuvant chemotherapy and those who did not in the group with invasive component size of $0.5 \mathrm{~cm}$ or less $(P=.29)$ and in the group with invasive component size of 0.5 to $2.0 \mathrm{~cm}(P=.50)$. However, the recurrence-free survival of patients who received adjuvant chemotherapy was significantly better than that of those who did not in the group with invasive component size greater than $2.0 \mathrm{~cm}(P=.009)$.
\end{abstract}

Conclusions: Pathologic invasive component size, as opposed to total tumor size, is associated more significantly with malignant behavior and prognosis and specifically should be considered before choosing candidates for adjuvant chemotherapy in pathologic stage I lung adenocarcinoma. (J Thorac Cardiovasc Surg 2013;146:580-5)

The widespread use of low-dose helical computed tomography (CT) for screening tumors has increased the early detection of smaller non-small cell lung cancer (NSCLC), particularly adenocarcinoma. ${ }^{1}$ Early lung adenocarcinomas often contain a lepidic growth component. ${ }^{2-4}$ In small lung adenocarcinoma, localized bronchioloalveolar carcinoma (adenocarcinoma in situ [AIS]) without foci of active fibroblastic proliferation showed no lymph node metastasis and a favorable prognosis. ${ }^{2}$ We hypothesized that the invasive component, not the lepidic growth component, is associated with malignancy and prognosis in lung adenocarcinoma. Therefore, we investigated and compared the usefulness of invasive component size, excluding the lepidic growth component, with that of the total tumor

From the Department of surgical Oncology, ${ }^{\mathrm{a}}$ Department of Pathology, ${ }^{\mathrm{b}}$ Hiroshima University, Hiroshima, Japan; and the Department of Thoracic Surgery, ${ }^{\mathrm{c}}$ Hyogo Cancer Center, Akashi, Japan.

Disclosures: Authors have nothing to disclose with regard to commercial support.

Received for publication Aug 23, 2012; revisions received Feb 8, 2013; accepted for publication April 18, 2013; available ahead of print June 17, 2013.

Address for reprints: Morihito Okada, MD, PhD, Department of Surgical Oncology, Research Institute for Radiation Biology and Medicine, Hiroshima University, 1-2-3-Kasumi, Minami-ku, Hiroshima City, Hiroshima 734-0037, Japan (E-mail: morihito@hiroshima-u.ac.jp).

0022-5223/ $\$ 36.00$

Copyright (C) 2013 by The American Association for Thoracic Surgery

http://dx.doi.org/10.1016/j.jtcvs.2013.04.032 size for determining the prognosis in patients with pathologic stage I lung adenocarcinoma. In addition, we examined the relationship between the adjuvant chemotherapy effects and invasive component sizes.

\section{PATIENTS AND METHODS \\ Patients}

We conducted a retrospective review of 603 consecutive cases of completely resected pathologic stage I lung adenocarcinomas from 2 institutions (Hiroshima University and Hyogo Cancer Center, Japan) between July 1, 2002, and December 31, 2011, to evaluate the significance of pathologic invasive component size. All patients who were staged according to the TNM Classification of Malignant Tumours, 7th edition, underwent curative $\mathrm{R} 0$ resections. ${ }^{5}$ The inclusion criteria comprised curative surgery without neoadjuvant chemotherapy or radiotherapy and a definitive histopathologic diagnosis of lung adenocarcinoma. Patients with incompletely resected tumors (R1 or R2) and those with multiple tumors or previous lung surgery were excluded from the analysis. Segmentectomy was considered in patients with clinical stage IA tumor, which could be removed completely with ample surgical margin. No lymph node metastasis was confirmed intraoperatively using rapid frozen section for enlarged lymph nodes or lymph nodes that were suspected to be diseased in the thoracic cavity. When nodal metastasis was apparent or doubtful, lobectomy was chosen instead. Systematic lymphadenectomy including hilar and mediastinal node dissection can be performed in segmentectomy, but not in wedge resection. Wedge resection therefore was performed for a tumor that consisted mainly of a ground-glass opacity component on highresolution $\mathrm{CT}$. 


$$
\begin{aligned}
& \text { Abbreviations and Acronyms } \\
& \begin{array}{ll}
\text { AIS } & =\text { adenocarcinoma in situ } \\
\text { AUC } & =\text { area under the curve } \\
\text { CT } & =\text { computed tomography } \\
\text { LY } & =\text { lymphatic invasion } \\
\text { MIA } & =\text { minimally invasive adenocarcinoma } \\
\text { NSCLC } & =\text { non-small cell lung cancer } \\
\text { PL } & =\text { pleural invasion } \\
\text { RFS } & =\text { recurrence-free survival } \\
\text { ROC } & =\text { receiver operating characteristic } \\
\text { V } & =\text { vascular invasion }
\end{array}
\end{aligned}
$$

The size of the invasive component was defined as the maximum dimension of the invasive component, excluding the lepidic growth component described previously. ${ }^{6}$ In case the tumor was small, the invasive component was measured under a microscope on a single slide. If the invasive component could not be measured on a single slide under the microscope because the tumor was large, then the invasive component size was calculated based on multiplying the total tumor size by the percentage of the invasive component. For example, if the total tumor size was assessed to be $4.0 \mathrm{~cm}$ by standard gross measurement and the invasive component was estimated to be $50 \%$ by pathologists, the invasive component size was determined to be $2.0 \mathrm{~cm}$. Adjuvant chemotherapy was considered for a patient whose total tumor size was larger than $2 \mathrm{~cm}$.

All patients who underwent lung resection were followed up from the day of surgery. Postoperative follow-up procedures including a physical examination, a chest roentgenogram every 3 months, and chest and abdominal CT examinations every 6 months were performed for the first 2 years, after which a physical examination and chest roentgenogram as well as a chest CT examination were performed every 6 months and 1 year, respectively.

This multicenter study was approved by the institutional review boards of the participating institutions; both institutions waived the requirement for informed consent from individual patients for this retrospective analysis of the prospective database.

\section{Statistical Analysis}

Data are presented as numbers (percentages) or the median unless otherwise stated. Pathologic malignant behavior was defined as positive lymphatic invasion (LY), vascular invasion (V), or pleural invasion (PL). To evaluate the predicting values for pathologic malignant behavior, receiver operating characteristic (ROC) curves of total tumor and invasive component sizes were used and area under the curve (AUC) values were compared. Recurrence-free survival (RFS) was defined as the interval between the surgery date and the first event (relapse or death from any cause) or the last follow-up visit. The RFS duration was analyzed using the Kaplan-Meier method. Differences in RFS were assessed using the log-rank test. A multivariate analysis with the Cox proportional hazards model using variables with a $P$ value less than .05 for univariate analysis was used to assess the potential independent effects of pathologic tumor size on RFS. A $P$ value less than .05 was considered statistically significant. The data were analyzed statistically using the Statistical Package for Social Sciences software (version 10.5; SPSS, Chicago, Ill).

\section{RESULTS}

The characteristics of the 603 study patients are summarized in Table 1 . The median follow-up period after surgery
TABLE 1. Patient characteristics

\begin{tabular}{lc}
\hline \multicolumn{1}{c}{ Variable } & $\mathbf{n}=\mathbf{6 0 3}$ \\
\hline Age, $\mathrm{y}, \mathrm{n}($ range $)$ & $67(31-89)$ \\
Sex, $\mathrm{n}(\%)$ & $306(50.7)$ \\
$\quad$ Male & \\
Pathologic tumor size, $\mathrm{n}$ (range) & $2.2(0.4-5.0)$ \\
$\quad$ Total $(\mathrm{cm})$ & $1.3(0-5.0)$ \\
$\quad$ Invasive component $(\mathrm{cm})$ & \\
p-Stage, $\mathrm{n}(\%)$ & $416(69.0)$ \\
IA & $187(31.0)$ \\
IB & \\
Lymphatic invasion, $\mathrm{n}(\%)$ & $124(20.6)$ \\
$\quad$ Positive & $105(17.4)$ \\
Vascular invasion, $\mathrm{n}(\%)$ & \\
$\quad$ Positive & $97(16.1)$ \\
Pleural invasion, $\mathrm{n}(\%)$ & $1(0.2)$ \\
$\quad$ Positive & $368(61.0)$ \\
Surgical procedure, $\mathrm{n}(\%)$ & $160(26.5)$ \\
$\quad$ Pneumonectomy & $74(12.3)$ \\
$\quad$ Lobectomy & \\
$\quad$ Segmentectomy & $141(23.4)$ \\
$\quad$ Wedge resection & \\
Adjuvant chemotherapy, $\mathrm{n}(\%)$ & \\
Yes & \\
\hline
\end{tabular}

was 48.7 months, during which the tumor recurred in 78 patients $(12.9 \%)$. The median size of the total tumor and its invasive component was $2.2 \mathrm{~cm}$ and $1.3 \mathrm{~cm}$, respectively. LY, V, and PL were evident in 124 (20.6\%), 105 (17.4\%), and $97(16.1 \%)$ patients, respectively. A total of 141 (23.4\%) patients underwent adjuvant chemotherapy and $131(92.9 \%)$ of 141 patients had a total tumor size of greater than $2 \mathrm{~cm}$. The chemotherapy regimen comprised cisplatin plus vinorelbine in 7 patients, carboplatin plus paclitaxel in 10 patients, gemcitabine plus tegafur-gimeracil-oteracil potassium in 2 patients, gemcitabine in 1 patient, tegafururacil in 94 patients, and tegafur-gimeracil-oteracil potassium in 27 patients.

The total tumor size in 280 patients $(46.4 \%)$ was $2 \mathrm{~cm}$ or less, and in 323 patients $(53.6 \%)$ was larger than $2 \mathrm{~cm}$ (Table 2). With regard to invasive component size, 181 patients $(30.0 \%)$ had a tumor measuring $0.5 \mathrm{~cm}$ or smaller, a so-called AIS or minimally invasive adenocarcinoma (MIA), 268 patients $(44.4 \%)$ had a tumor measuring 0.5 to $2 \mathrm{~cm}$, and 154 patients $(25.5 \%)$ had a tumor measuring larger than $2 \mathrm{~cm}$.

Figure 1 shows the ROC curves of total tumor and invasive component sizes for predicting the pathologic malignant behavior (LY, V, or PL). The AUC values of total tumor and invasive component sizes were 0.673 (95\% confidence interval [CI], 0.627-0.719) and 0.819 (95\% CI, 0.786-0.852), respectively. The predictability of pathologic malignant behavior based on the invasive component size was better than that based on the total tumor size. 
TABLE 2. Discrepancy between total tumor size and invasive component size

\begin{tabular}{lrcc}
\hline & \multicolumn{3}{c}{ Invasive component size } \\
\cline { 2 - 4 } & $\leq \mathbf{0 . 5} \mathbf{~ c m}$ & $\mathbf{0 . 5 - 2 . 0} \mathbf{~ c m}$ & $>\mathbf{2 . 0} \mathbf{~ c m}$ \\
\hline Total tumor size, $\mathrm{n}$ & & & \\
$\leq 2.0 \mathrm{~cm}(\mathrm{n}=280)$ & 132 & 148 & \\
$>2.0 \mathrm{~cm}(\mathrm{n}=323)$ & 49 & 120 & 154 \\
Total $(\mathrm{n}=603)$ & 181 & 268 & 154 \\
\hline
\end{tabular}

There were significant differences in RFS among patients with an invasive component size of $0.5 \mathrm{~cm}$ or smaller (5-year RFS rate, $96.6 \%$ ), 0.5 to $2.0 \mathrm{~cm}$ (5-year RFS rate, $70.6 \%$ ), and larger than $2.0 \mathrm{~cm}$ (5-year RFS rate, $62.2 \%$ ) (Figure 2).

The multivariate analysis included age, sex, pathologic tumor size, LY, V, and PL. It showed that age, sex, invasive component size, and LY were independent prognostic factors for RFS, whereas total tumor size was not (Table 3).

The adjuvant chemotherapy effects in each subgroup based on invasive component size were investigated. There were no differences in RFS between patients who received adjuvant chemotherapy and those who did not in the group with an invasive component size of $0.5 \mathrm{~cm}$ or smaller (5-year RFS, $90.0 \%$ vs $97.1 \% ; P=.29$ ) (Figure $3, A$ ) and 0.5 to $2.0 \mathrm{~cm}$ (5-year RFS, $77.9 \%$ vs $69.4 \% ; P=.50$ ) (Figure $3, B$ ). In contrast, there was a significant difference in RFS between patients who received adjuvant chemotherapy and those who did not in the group with an invasive component size larger than $2.0 \mathrm{~cm}$ (5-year RFS, $78.6 \%$ vs $53.1 \% ; P=.009$ ) (Figure 3,C).

\section{DISCUSSION}

Based on our hypothesis that the pathologic invasive component, excluding the tumor lepidic growth, determines malignancy and prognosis, we investigated the prognostic significance of invasive component size compared with that of total tumor size in patients with pathologic stage I lung adenocarcinoma.

The ROC-AUC for predicting pathologic malignant behavior (LY, V, or PL) was considerably larger for the invasive component size than for the total tumor size, indicating that the size of the invasive component, not the total tumor, reflects the pathologic malignant behavior.

With regard to RFS, multivariate Cox analysis showed that the invasive component size and LY, which is a prognostic factor for lung adenocarcinoma, ${ }^{7,8}$ were independent prognostic factors but total tumor size was not, indicating that the invasive component size more closely correlates with survival than the total tumor size. Furthermore, we divided the patients into 3 groups based on the invasive component size with significant differences in RFS and observed that patients with an invasive component size smaller than $0.5 \mathrm{~cm}$ (AIS or MIA) had excellent prognoses. Because invasive component size more closely correlated with pathologic malignant behavior and prognosis than total tumor size, invasive tumor size would be suitable for the T-descriptor in TNM classification. Several reports regarding the invasive component size in lung adenocarcinoma have been published. ${ }^{6,9-11}$ One report showed that mixed subtype with predominant bronchioloalveolar carcinoma component in the 5-mm or smaller invasive component group (MIA) as well as the pure bronchioloalveolar carcinoma group (AIS) showed no lymph node metastasis and excellent prognosis in early

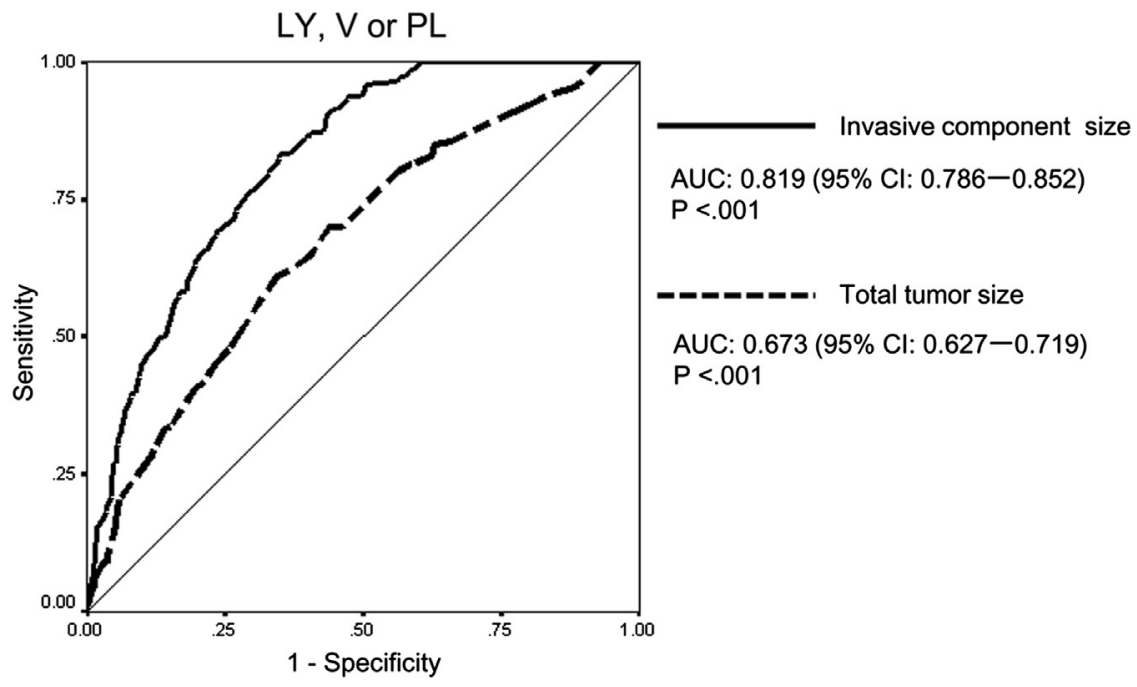

FIGURE 1. ROC-AUC values of total tumor and invasive component sizes used for predicting pathologic malignant behavior (LY, V, or PL). The invasive component size predicted the pathologic malignant behavior better than the total tumor size. $C I$, Confidence interval; $A U C$, area under the curve; $L Y$, lymphatic invasion; $V$, vascular invasion; $P L$, pleural invasion. 


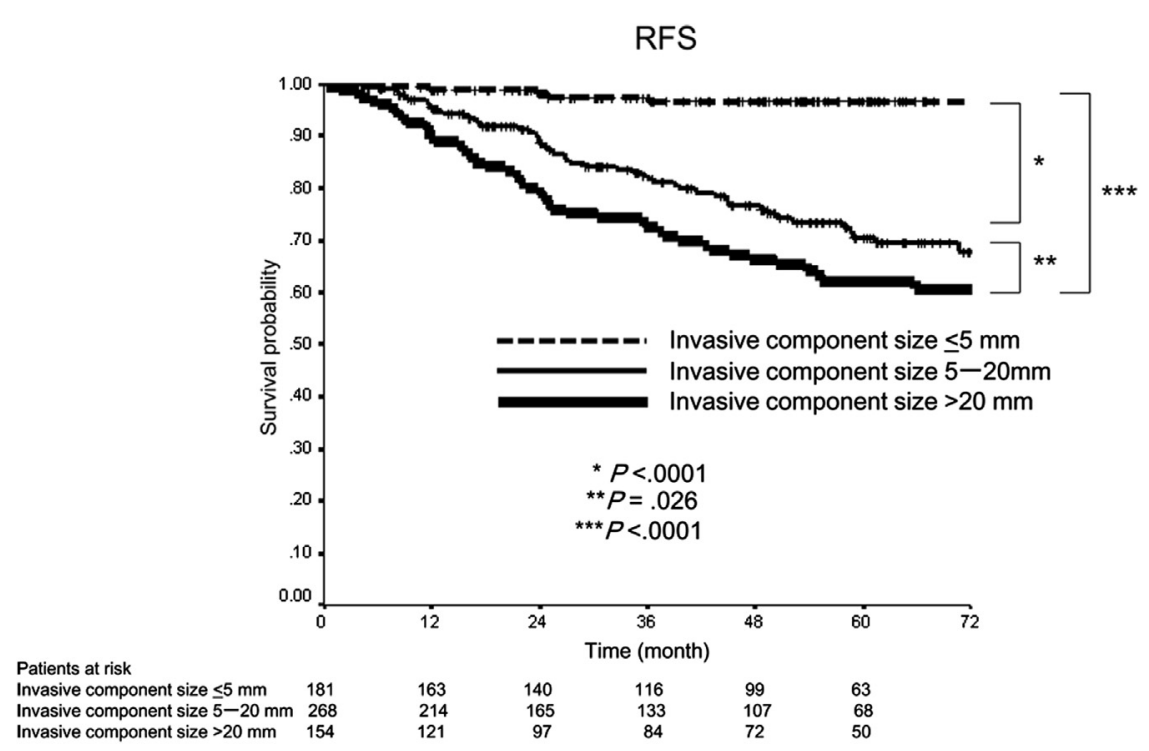

FIGURE 2. There were significant differences in RFS among patients with an invasive component size of $0.5 \mathrm{~cm}$ or smaller ( 5 -year RFS rate, $96.6 \%$ ), 0.5 to $2.0 \mathrm{~cm}$ (5-year RFS rate, 70.6\%), and larger than $2.0 \mathrm{~cm}$ (5-year RFS rate, 62.2\%). RFS, Recurrence-free survival.

stage lung adenocarcinoma. ${ }^{11}$ Another study reported that invasive tumor size was associated more significantly with disease-free survival than total tumor size. ${ }^{6}$ Our present findings are consistent with these reports. In addition to $47.1 \%$ of T1a tumors, $15.2 \%$ of tumors more than $2 \mathrm{~cm}$ were found to have an invasive component of $0.5 \mathrm{~cm}$ or less. In total, $30.0 \%$ of pathologic stage I lung adenocarcinoma patients belong to AIS or MIA, which shows excellent prognosis after complete resection.

There are several implications of the updated adenocarcinoma classification for staging that should be considered for the next revision of the TNM classification. ${ }^{4}$ One is that the total tumor size ( $\mathrm{T}$ factor) may require a substitution of invasive component size only. We previously reported that solid tumor size on high-resolution CT was more useful

TABLE 3. Multivariate Cox regression analysis of RFS

\begin{tabular}{lcc}
\hline \multicolumn{1}{c}{ Variable } & $\begin{array}{c}\text { Hazard ratio } \\
(\mathbf{9 5} \% \text { confidence interval) }\end{array}$ & $\boldsymbol{P}$ value \\
\hline Model 1 & & \\
Age & $1.05(1.02-1.07)$ & $<.001$ \\
Sex (male) & $2.02(1.30-3.11)$ & .002 \\
Total tumor size (cm) & $1.20(.99-1.46)$ & .068 \\
Lymphatic invasion & $2.98(1.88-4.71)$ & $<.001$ \\
Vascular invasion & $1.58(0.96-2.61)$ & .075 \\
Pleural invasion & $1.15(0.71-1.86)$ & .57 \\
Model 2 & & \\
Age & $1.05(1.03-1.07)$ & $<.001$ \\
Sex (male) & $1.91(1.24-2.96)$ & .004 \\
Invasive component size (cm) & $1.30(1.10-1.54)$ & .002 \\
Lymphatic invasion & $2.74(1.74-4.33)$ & $<.001$ \\
Vascular invasion & $1.35(0.81-2.24)$ & .25 \\
Pleural invasion & $1.10(0.68-1.77)$ & .70 \\
\hline
\end{tabular}

for predicting pathologic invasiveness, lymph node metastasis, and prognosis than whole tumor size in clinical stage IA lung adenocarcinoma. ${ }^{12-14}$ Clinically and pathologically, the sizes of the solid or invasive component using CT and pathology examinations are more useful for predicting survival than those of the total tumor. We strongly recommend that solid tumor size on CT and invasive component size be used to determine the $\mathrm{T}$ factor in the TNM classification of lung cancer. Another interest is histologic subtype of adenocarcinoma for predicting prognosis. The differences in substantial survival among adenocarcinomas with aggressive (solid or micropapillary), intermediate (acinar or papillary), or indolent features (lepidic) were shown. ${ }^{15,16}$ Although this study did not include histologic subtype data, in addition to the histologic subtyping, invasive component size was reported to be an independent prognostic factor in pathologic stage I lung adenocarcinoma. ${ }^{6}$ Molecular research studies including genomic, proteomic, or both also have the potential to predict more accurate subclassification of the malignant aggressiveness of adenocarcinoma. ${ }^{4}$ The histologic subtype and molecular findings represent quality of tumors whereas invasive component size represent quantity of tumors. Further study is warranted to determine which factors are suitable to be included in the T-factor from the viewpoint of quality and quantity of the tumor.

Accurate staging that reflects prognosis is important to select optimal patients for adjuvant chemotherapy. Adjuvant chemotherapy for pathologic stage I NSCLC is controversial. ${ }^{17}$ It has been suggested that platinum-based adjuvant chemotherapy may benefit patients with tumors $4 \mathrm{~cm}$ or larger in stage IB NSCLC. ${ }^{18}$ Randomized phase III trials and meta-analysis revealed that tegafur-uracil 
RFS: invasive component size $\leq 0.5 \mathrm{~cm}$

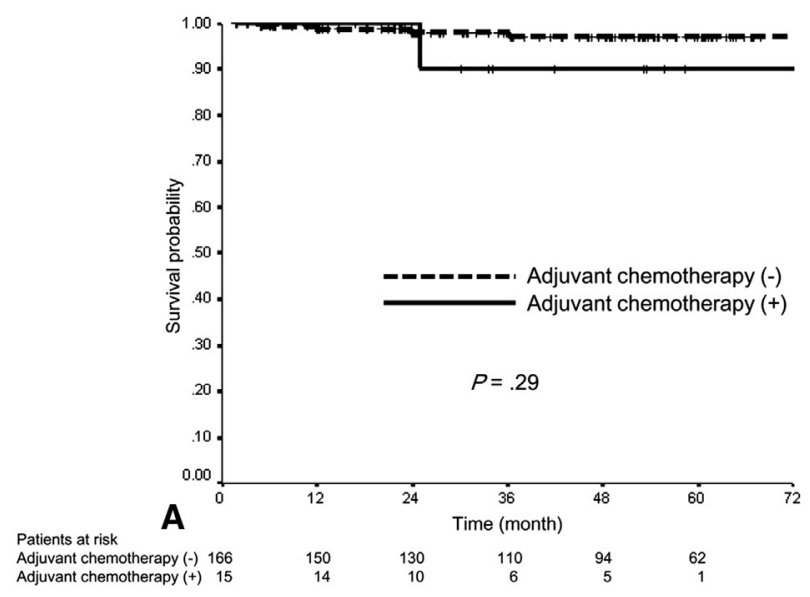

RFS: invasive component size $0.5-2.0 \mathrm{~cm}$

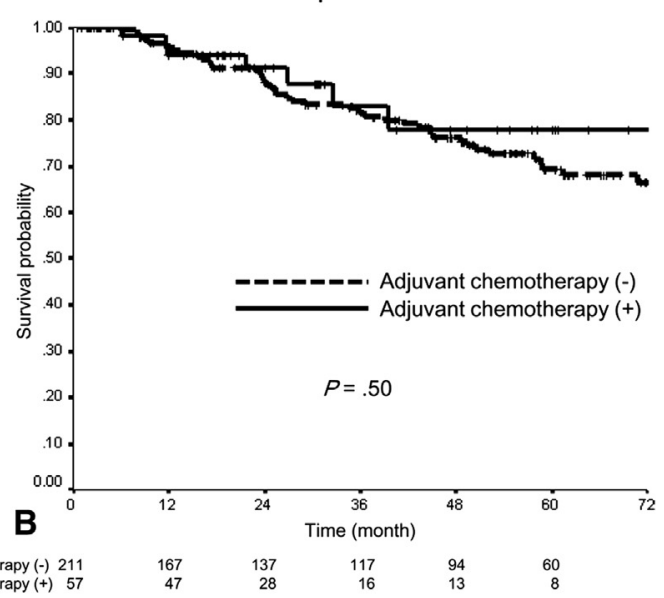

RFS: invasive component size $>2.0 \mathrm{~cm}$

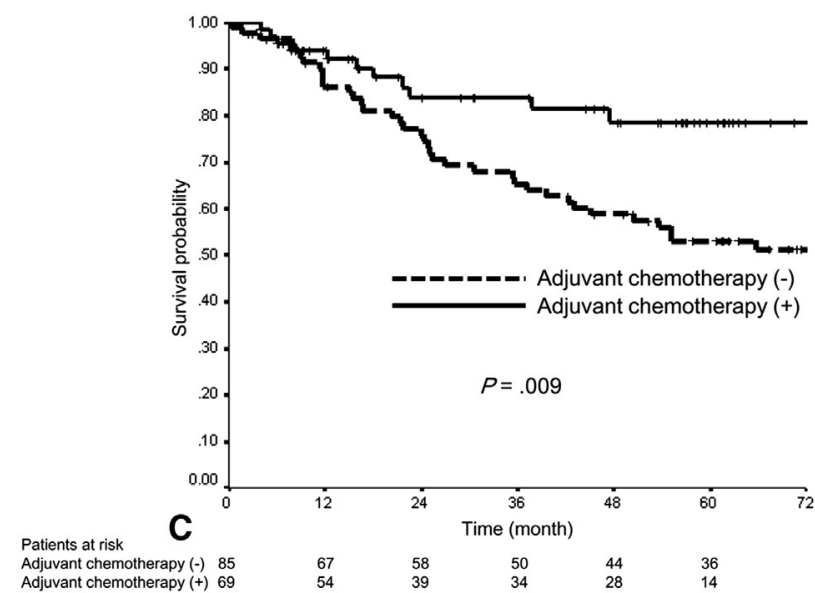

FIGURE 3. A, There were no differences in RFS between patients who received adjuvant chemotherapy and those who did not in the group with an invasive component size of $0.5 \mathrm{~cm}$ or less (5-year RFS, $90.0 \%$ vs $97.1 \% ; P=.29$ ). B, There were no differences in RFS between patients who received adjuvant chemotherapy and those who did not in the group with an invasive component size of 0.5 to $2.0 \mathrm{~cm}$ (5-year RFS, $77.9 \%$ vs $69.4 \% ; P=.50$ ). C, There was a significant difference in RFS between patients who received adjuvant chemotherapy and those who did not in the group with an invasive component size of larger than $2.0 \mathrm{~cm}$ (5-year RFS, $78.6 \%$ vs $53.1 \% ; P=.009)$. $R F S$, Recurrence-free survival.

significantly improves survival in patients with stage I NSCLC, particularly lung adenocarcinomas larger than $2 \mathrm{~cm} \cdot{ }^{19-21}$ Selecting optimal patients who would benefit from adjuvant chemotherapy can prevent unnecessary chemotherapy. We evaluated the effect of adjuvant chemotherapy in each subgroup divided on the basis of invasive component size. In this study, patients with an invasive tumor size of $2 \mathrm{~cm}$ or less did not benefit from adjuvant chemotherapy, whereas those with an invasive tumor size larger than $2 \mathrm{~cm}$ did. Although $92.9 \%$ of patients who underwent adjuvant chemotherapy had a total tumor size larger than $2 \mathrm{~cm}$, approximately $50 \%$ of these patients had an invasive component $2 \mathrm{~cm}$ or smaller. Therefore, candidates for adjuvant chemotherapy in stage I lung adenocarcinoma should be selected on the basis of invasive component size. Patients with AIS or MIA and also those with an invasive component size of 0.5 to $2 \mathrm{~cm}$ would not benefit from adjuvant chemotherapy.

The retrospective nature of the analysis was a limitation of this study. Therefore, prospective studies are required to evaluate the effects of adjuvant chemotherapy for each patient group subdivided on the basis of invasive component size.

In conclusion, invasive component size, excluding lepidic growth, has a higher predictive value for pathologic malignant behavior and prognosis than total tumor size and aids in selecting optimal candidates for adjuvant chemotherapy among patients with pathologic stage I lung adenocarcinoma. We highly recommend using invasive component size as the new T descriptor in TNM classification of lung cancer. 


\section{References}

1. National Lung Screening Trial Research Team, Aberle DR, Adams AM, Berg CD, Black WC, Clapp JD, Fagerstrom RM, et al. Reduced lung-cancer mortality with low-dose computed tomographic screening. N Engl J Med. 2011;365: 395-409.

2. Noguchi M, Morikawa A, Kawasaki M, Matsuno Y, Yamada T, Hirohashi S, et al. Small adenocarcinoma of the lung: histologic characteristics and prognosis. Cancer. 1995; 75:2844-52.

3. Okada M, Nishio W, Sakamoto T, Uchino K, Hanioka K, Ohbayashi C, et al. Correlation between computed tomographic findings, bronchioloalveolar carcinoma component, and biologic behavior of small-sized lung adenocarcinomas. J Thorac Cardiovasc Surg. 2004;127:857-61.

4. Travis WD, Brambilla E, Noguchi M, Nicholson AG, Geisinger KR, Yatabe Y, et al. International Association for the Study of Lung Cancer/American Thoracic Society/European Respiratory Society International Multidisciplinary Classification of lung adenocarcinoma. J Thorac Oncol. 2011;6:244-85.

5. Goldstraw P, Crowley J, Chansky K, Giroux DJ, Groome PA, Rami-Porta R, et al, International Association for the Study of Lung Cancer International Staging Committee, participating institutions. The IASLC Lung Cancer Staging Project: proposals for the revision of the TNM stage groupings in the forthcoming (seventh) edition of the TNM Classification of Malignant Tumours. J Thorac Oncol. 2007;2:706-14.

6. Yoshizawa A, Motoi N, Riely GJ, Sima CS, Gerald WL, Kris MG, et al. Impact of proposed IASLC/ATS/ERS classification of lung adenocarcinoma: prognostic subgroups and implications for further revision of staging based on analysis of 514 stage I cases. Mod Pathol. 2011;24:653-64.

7. Goldstein NS, Mani A, Chmielewski G, Welsh R, Pursel S. Prognostic factors in T1 N0 M0 adenocarcinomas and bronchioloalveolar carcinomas of the lung. Am J Clin Pathol. 1999;112:391-402.

8. Funai K, Sugimura H, Morita T, Shundo Y, Shimizu K, Shiiya N. Lymphatic vessel invasion is a significant prognostic indicator in stage IA lung adenocarcinoma. Ann Surg Oncol. 2011;18:2968-72.

9. Borczuk AC, Qian F, Kazeros A, Eleazar J, Assaad A, Sonett JR, et al. Invasive size is an independent predictor of survival in pulmonary adenocarcinoma. Am J Surg Pathol. 2009;33:462-9.

10. Sakao Y, Miyamoto H, Sakuraba M, Oh T, Shiomi K, Sonobe S, et al. Prognostic significance of a histologic subtype in small adenocarcinoma of the lung: the impact of nonbronchioloalveolar carcinoma components. Ann Thorac Surg. 2007; 83:209-15.

11. Yim J, Zhu LC, Chiriboga L, Watson HN, Goldberg JD, Moreira AL. Histologic features are important prognostic indicators in early stages lung adenocarcinomas. Mod Pathol. 2007;20:233-41.
12. Tsutani Y, Miyata Y, Nakayama H, Okumura S, Adachi S, Yoshimura M, et al. Prognostic significance of using solid versus whole tumor size on highresolution computed tomography for predicting the pathological malignant grade of tumors in clinical stage IA lung adenocarcinoma: a multicenter study. J Thorac Cardiovasc Surg. 2012;143:607-12.

13. Tsutani Y, Miyata Y, Nakayama H, Okumura S, Adachi S, Yoshimura M, et al. Prediction of pathological node-negative clinical stage IA lung adenocarcinoma for optimal candidates undergoing sublobar resection. J Thorac Cardiovasc Surg. 2012;144:1365-71.

14. Tsutani Y, Miyata Y, Yamanaka T, Nakayama H, Okumura S, Adachi S, et al Solid tumors versus mixed tumors with a ground-glass opacity component in patients with clinical stage IA lung adenocarcinoma: prognostic comparison using high-resolution computed tomography findings. J Thorac Cardiovasc Surg. 2012. December 12, 2012 [Epub ahead of print].

15. Russell PA, Wainer Z, Wright GM, Daniels M, Conron M, Williams RA. Does lung adenocarcinoma subtype predict patient survival? A clinicopathologic study based on the new International Association for the Study of Lung Cancer/American Thoracic Society/European Respiratory Society international multidisciplinary lung adenocarcinoma classification. J Thorac Oncol. 2011;6:1496-504.

16. Warth A, Muley T, Meister M, Stenzinger A, Thomas M, Schirmacher P, et al. The novel histologic International Association for the Study of Lung Cancer/ American Thoracic Society/European Respiratory Society classification system of lung adenocarcinoma is a stage-independent predictor of survival. J Clin Oncol. 2012;30:1438-46.

17. Gandara DR, Wakelee H, Calhoun R, Jablons D. Adjuvant chemotherapy of stage I non-small cell lung cancer in North America. J Thorac Oncol. 2007;2: S125-7.

18. Strauss GM, Herndon JE 2nd, Maddaus MA, Johnstone DW, Johnson EA Harpole DH, et al. Adjuvant paclitaxel plus carboplatin compared with observation in stage IB non-small-cell lung cancer: CALGB 9633 with the Cancer and Leukemia Group B, Radiation Therapy Oncology Group, and North Central Cancer Treatment Group Study Groups. J Clin Oncol. 2008;26:5043-51.

19. Kato H, Ichinose Y, Ohta M, Hata E, Tsubota N, Tada H, et al. A randomized trial of adjuvant chemotherapy with uracil-tegafur for adenocarcinoma of the lung. $N$ Engl J Med. 2004;350:1713-21.

20. Hamada C, Tanaka F, Ohta M, Fujimura S, Kodama K, Imaizumi M, et al. Metaanalysis of postoperative adjuvant chemotherapy with tegafur-uracil in nonsmall-cell lung cancer. J Clin Oncol. 2005;23:4999-5006.

21. Hamada C, Tsuboi M, Ohta M, Fujimura S, Kodama K, Imaizumi M, et al. Effect of postoperative adjuvant chemotherapy with tegafur-uracil on survival in patients with stage IA non-small cell lung cancer: an exploratory analysis from a meta-analysis of six randomized control trials. J Thorac Oncol. 2009;4:1511-6. 